\title{
Tactics for Improvement of Combination between IE Education and Engineering Practice by Exploring Historical Employment Statistics
}$$
\text { Luo Yabo }{ }^{1, a} \text {, Li Xia }{ }^{1, b}
$$ \\ ${ }^{1}$ School of Mechanical and Electronic Engineering, Wuhan University of Technology, Wuhan, \\ 430070, China \\ a email: luoyabo1973@163.com, bemail: guoguozhaopian@163.com
}

Keywords: Industrial Engineering; Personnel Cultivation; Comparative Education; Practice-based Education

\begin{abstract}
Industrial Engineering (IE) is a comprehensive and practical emerging major. Due to unclear definition of professional field, there is a certain disparity between IE education in high school and engineering practice. To find the approach to bridge the gap, this paper analyzed IE comparative education characteristics between America and China and the key bottleneck of IE engineering education in domestic high schools. Based on the comparative analysis and the employment statistical data, it can be concluded that domestic IE education is greatly lagged the demand of enterprises, and bridging the gap between IE education and engineering practice is one of the most important things to improve IE. Finally, some practical tactics involving six items to bridge the IE education and engineering practice were proposed.
\end{abstract}

\section{Introduction}

IE has experienced a long-time development since it was putting forward last century. Modern IE is a kind of optimization technology, which faces the whole process of enterprise management. The ultimate pursuit is the best efficiency of system. The main features can also be summarized for engineering, sociality, interface and innovation [1, 2]. Under the rapid development of market economy, the requirement of enterprise is higher, but the education methods and teaching modes are greatly lagged, which causes enterprises cannot recruit proper employees, and at the same time, hundreds of graduates fail to find the appropriate job.

\section{Present Higher Education of IE at Home and Abroad}

The objective of Engineer 2020 is to provide students with opportunities to participate in real-world projects to provide them with skills they will need in workplace [3, 4]. Throughout the IE education in America, the main characteristics can be summed up as follows:

(1) They take local economy and social needs as basis, the background is clearly highlighted which is conducive to formulate the teaching contents.

(2) High recognition of IE in American Society. IE is defined as one of the seven engineering majors in America, many experts and scholars are putting large number of time and energy to constantly explore new training modes and curriculum contents.

(3) With the development of IE, the curricula consummate constantly. The training objectives and training methods transfer from theory to practice, and from indoor to outdoor practice.

(4) Pay attention to cultivate independence of students and to improve their innovative thinking and IE consciousness.

In China, since 1992, Xi'an Jiaotong University and Tianjin University have set up the first batch of IE professional education. Then, universities throughout the country began to set up IE and classified it in different institutes. For example, management institute, mechanical institute and other engineering institutes [5]. They teach students in traditional way, which students are under a passive learning state as audiences. In addition to theory teaching, most schools provide students with field practice, curriculum design and graduation practice. However, the socialization of practice is not high, the patterns and contents are monotonous, and process controlling is loose [6]. In recent years, some enterprises gradually began to support IE education. For example, Foxconn 
set up research center in Tsinghua University, which integrates the results of IE application. Events like these promote the exchange and development of IE, and also help students apply their theory in practical. More important, these can help students realize the enormous value of IE for enterprises, and due to this, IE gradually become public in China [7].

The characteristics of IE in domestic colleges can be seen by the way of IE education.

(1) The backgrounds of IE are directed by the educational characteristics of universities.

(2) IE is an emerging discipline in China, and is still under exploration, traditional teaching way can help students memorize textbook knowledge but cannot help them well apply it.

(3) The understanding of IE is not enough, theory teaching is paid much attention and practice application is less emphasized. Moreover, the practice designed by schools does not play ideal role.

Not only education way exists large differences between China and America but also others. Next, different curricula are put together to find more differences as Fig.1.

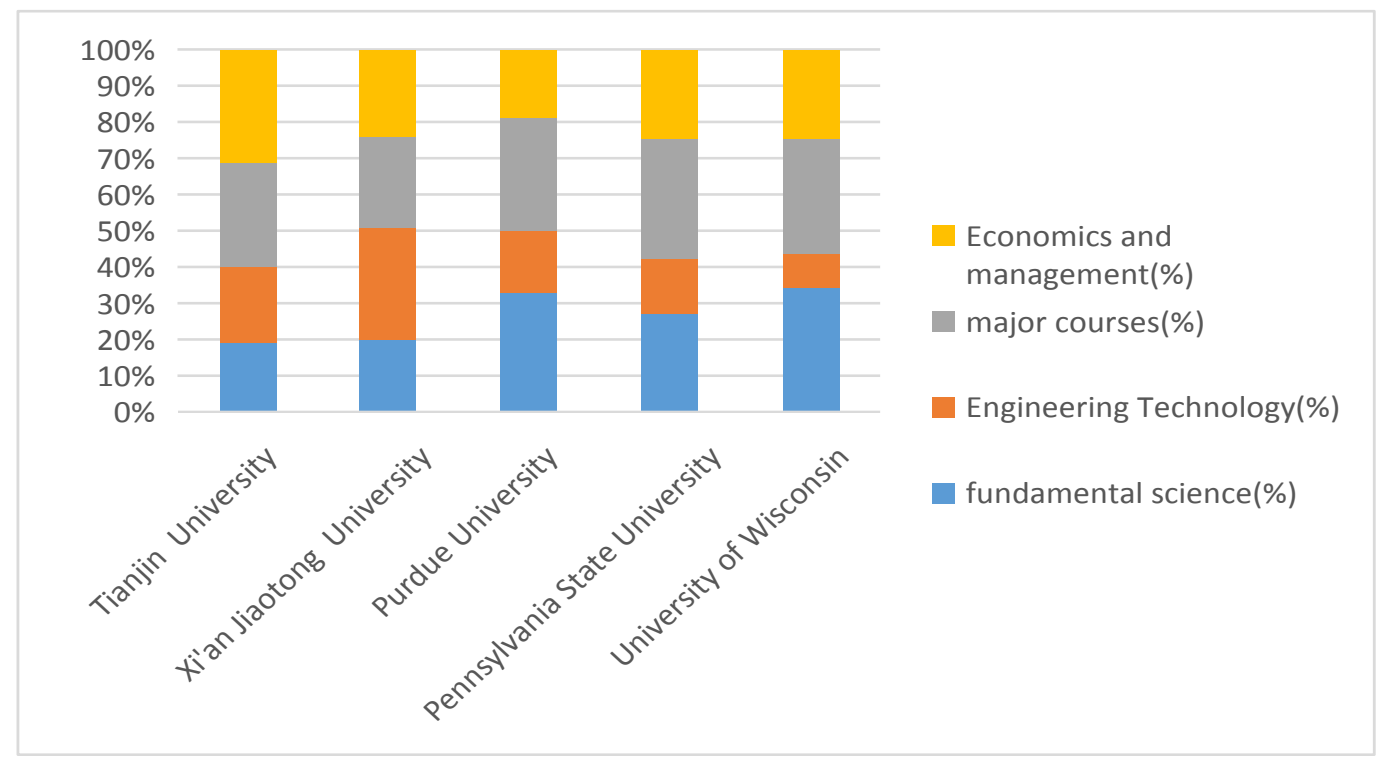

Fig.1 Comparisons of knowledge structure between Chinese and American

Combining Fig.1 with IE education, which indicates American universities pay more stress to cultivate basic ability and IE consciousness of students; in contrast, domestic IE education weakens basic courses, while putting more on technical and management courses.

Due to distributed nature of domestic education and insufficient autonomy of students, our IE education did not reach ideal level. After four years learning, students step into society working various forms of work.

Statistics show that IE employment ranges widely, throughout manufacturing industry. IE engineers engage in manufacturing and processing, and in management and technical supporting. Nowadays, electronic commerce gradually replaces traditional retail, which puts logistics industry gradually on rise. According to this, IE will be applied in logistics and supply chain management more and more often, the development prospect of which is spacious.

\section{Problems Faced by IE Education in China}

With increasing of demand for IE talents day by day, there are still some contradictions for companies and graduates, for example, companies cannot recruit the needed employees, and IE graduates find it hard to apply a suitable job.

(1) Professional orientation is not clear. IE is generally regarded as a major and is classified in mechanical or management institute in China. Moreover, IE is often taken as the management among engineering, and the education of IE has no accurate orientation, thus leading to the specialization of teaching content is not high.

(2) The form of practice is greater than the content resulting that students are strange into production process. So when they take part in job, their enterprises still need to invest a lot of time and money in training. Fig.2 shows the importance of experience when looking for a job. 


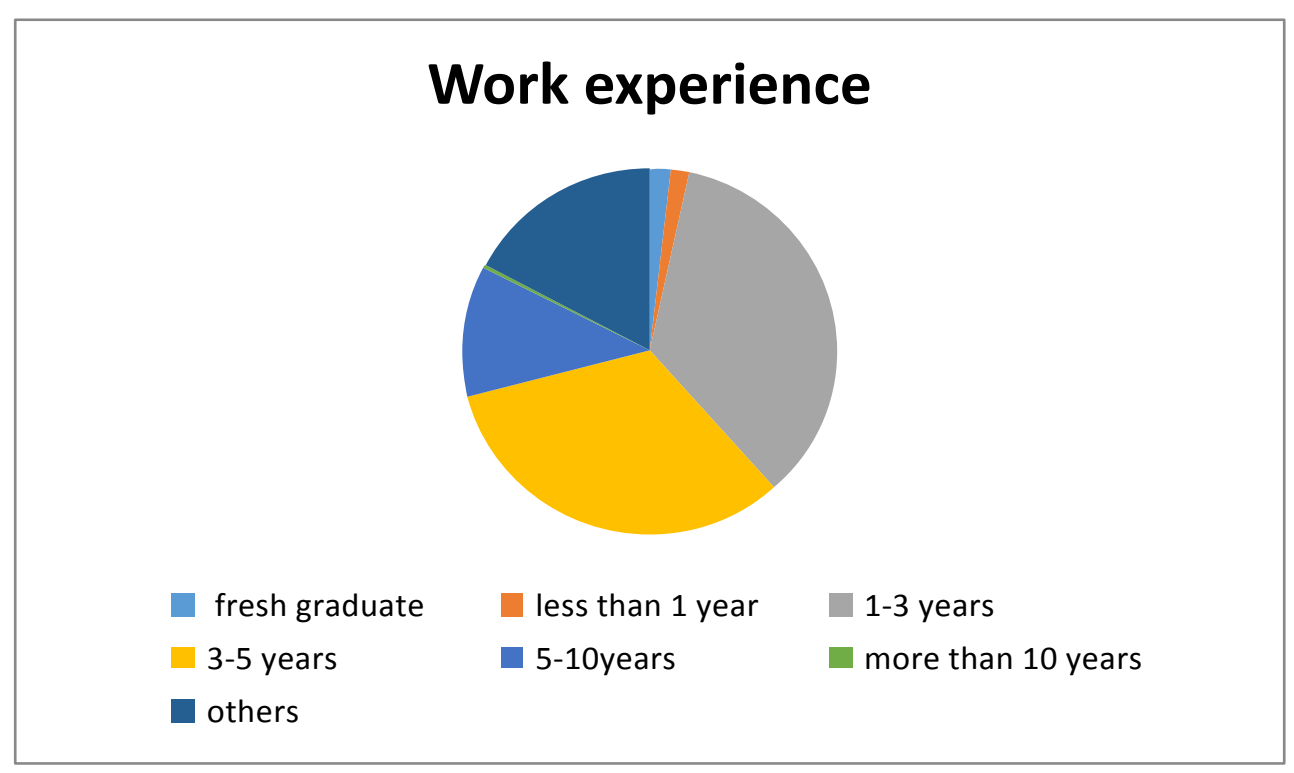

Fig.2 The importance of experience when looking for a job

Fig. 2 shows that graduates may have difficulty finding proper job since they have no experience in school, which will add more pressure to employment.

(3) Learning content with basic subject and learning time is insufficient. IE takes logistics, physics and other natural sciences as foundation to optimize system. Take operation research in Wuhan University of technology as an example, learning time is only one semester for 36 hours, resulting in a lack of learning content and learning depth.

(4) Students themselves do not pay enough attention to IE. Some students do not really understand the core of IE because of the regardless of their IE education in school. So they may look down on it, therefore whose learning attitude needs to be improved.

The work that IE engaged in enterprises and the proportion of which is shown in Table 1:

Table 1 The job of IE in companies

\begin{tabular}{ccccccc}
\hline Job & Engineering & Production & Sales & Quality management & Purchasing & Others \\
\hline Rates(\%) & 33.1 & 20.4 & 8.7 & 4.8 & 3.8 & 29.3 \\
\hline
\end{tabular}

The work of IE engineers involves a wide range, but professional characteristics are not obvious, so they may neglect job content of long-term and can be taken as technical personnel.

(1) Lacking awareness of IE in Enterprises. IE Engineers need to get support and cooperation from business leaders and staffs. However, domestic enterprises have no IE background, so it is difficult to realize the benefits IE can bring them, and thus ignoring the value of IE staff.

(2) It is difficult to form standards, and it is more difficult to modify standards. When it comes to operation, operators do not necessarily work according to standards designed by engineers to pledge production. At the same time, once standard formed, they do not want to change more.

(3) IE supporting systems and tools are deficient. Actual production varies from industry to industry, from company to company. There is no adaptable system or tools to specific company.

(4) The foundation of Chinese manufacturing industry is still very weak. The best improvement is in the preliminary design of the products, but Chinese make is in the middle and lower in the global industrial chain, the added value is low, so it is hard to improve from source.

\section{Conclusions}

In view of above analysis, some conclusions are put forward to IE education:

(1)Strengthening professional background of IE and carrying out the mode of classified training. Universities implemented IE can make clear training directions according to school's teaching expertise, and implement the classification training modes, schools can set up reasonable courses and strengthen engineering education to train compound talents.

(2) Promoting IE master's education and enhancing understanding of IE. At present, Chinese IE 
education pays more attention to undergraduate cultivation which results in Chinese IE personnel only at the entry stage, so we are lack of specialized researchers. Due to this, our education can strengthen the master and doctor education, with professional and technical personnel entering enterprises to strengthen the influence of IE in enterprises.

(3) Strengthening cooperation between colleges and enterprises. There are large gaps between education and enterprises' demand, resulting in a serious loss of IE professionals. Enterprises can cooperate with schools, sponsor matches and provide opportunities for students to practice.

(4) Promoting development of related tools and supporting systems. The implementation of IE improvement schemes needs technical support and cooperation, so IE engineers should pay attention to engineering and management, and can apply IE to solve the technical problems.

(5) Enhancing independent innovation of enterprises to lay a good foundation for source design. Good improvement can avoid unnecessary waste, but due to the weak independent research and development capacity, we can only carry out improvement in production, which cannot avoid waste actually. Chinese high education should focus on the ability of innovation of students, and apply their knowledge to innovative, design, research, and to cultivate.

(6) Enterprises should also pay attention to the training and development of talents. For example, take enterprise as a learning unit to learn related knowledge from corporate executives to grassroots levels, or they can also combine with local colleges to organize activities.

With the development of society, the application of IE will be more and more widely used. IE already had a high recognition degree in manufacturing, supply chain, electronic commerce and trades. If IE can be well combining with practice, and has better and more clearly professional background and defined professional education contents, IE would also have a better application prospect.

\section{Acknowledgment}

This research is funded by the key education research project of Wuhan University of Technology (No.2013028) and the National Natural Science Fund of China (51375357).

\section{References}

[1]. Jian Yao, Benshi Chen, Research on the reform of basic industrial engineering courses[J]. Education Exploration, 2013, 03:35-36. (In Chinese)

[2]. Stefanovic, M., The objectives, architectures and effects of distance learning laboratories for industrial engineering education. Computers \& Education 2013, 69, 250-262.

[3]. Page, L. T.; Stanley, L. M., Ergonomics Service Learning Project: Implementing an Alternative Educational Method in an Industrial Engineering Undergraduate Ergonomics Course. Human Factors and Ergonomics in Manufacturing \& Service Industries 2014, 24 (5), 544-556.

[4].Brahimi Nadjib, Dweiri Fikri, Alsyouf Imad, Khan Sharfuddin A. Implementing co-operative education in an industrial engineering program in the United Arab Emirates: Experience and lessons learned. International Journal of Engineering Education, 2013, 29(5), 1238-1247.

[5]. Guoming Wan, Zhenfu Jian. Tai wan IE theory and review of application development[J]. Industry Engineering, 2003, 3, 1-5-23. (In Chinese)

[6]. Huaizhen Yang, Lei Li. The comparative study of Chinese and American Industrial Engineering Undergraduate Education[J]. Chinese Adult Education, 2010, 21:132-134. (In Chinese)

[7]. JIN Qing, LI Wei- hong. Inves tigation of the Employment Condition of IE Graduates[J]. Equipment Manufacturing Technology, 2008, 06:124-127. (In Chinese) 